\title{
Presence of $\gamma$-aminobutyric acid transporter mRNA in interneurons and principal cells of rat hippocampus
}

\author{
Christiane Frahm*, Dominique Engel, Antje Piechotta, Uwe Heinemann, \\ Andreas Draguhn
}

Johannes-Müller-Institut für Physiologie der Charité, Humboldt-Universität, Tucholskystrasse, 210117 Berlin, Germany

Received 18 May 2000; accepted 19 May 2000

\begin{abstract}
After release, neurotransmitters are removed from the extracellular space by high-affinity uptake. Specific sodiumdependent transporters serve this function for the inhibitory transmitter $\gamma$-aminobutyric acid (GABA). However, it is largely unknown to which proportion GABA is taken up by GABAergic interneurons, glia cells or principal neurons. We analyzed the distribution of mRNA for the main GABA-transporter subtype in the hippocampus, GAT-1, in adult rats. Most interneurons were strongly stained for GAT-1 mRNA, indicating re-uptake by the GABA-releasing cells. Surprisingly, prominent signals for GAT-1 were also found throughout the principal cell layers (granule and pyramidal cells). These data indicate that GABA transporters may be present in non-GABAergic projection cells of the rat hippocampus which contribute to the clearance of GABA from the extracellular space. (c) 2000 Elsevier Science Ireland Ltd. All rights reserved.
\end{abstract}

Keywords: $\gamma$-Aminobutyric acid uptake; Inhibition; Interneurons; In situ hybridization; Glutamate dehydrogenase; Hippocampus

$\gamma$-Aminobutyric acid (GABA) is the dominant inhibitory neurotransmitter in the mammalian brain and is released from specialized interneurons. After synaptic release, GABA is taken up into cells by sodium-dependent, electrogenic transport. This GABA uptake limits the duration of inhibitory postsynaptic potentials $[3,4]$ and reduces background GABA levels in the extracellular environment [10]. It is largely unknown into which cells GABA is taken up after synaptic release. A fraction of the transmitter will be transported back into the presynaptic terminal, where it may be re-used in subsequent release processes. The remaining GABA must be taken up by adjacent astrocytes or by the postsynaptic target neuron. The latter cells will feed the transmitter into the Krebs cycle which may cause depletion of GABA and disinhibition after sustained high activity of interneurons [15]. Therefore, it is important to know the cellular distribution of GABA-transporters. While four genetically related GABA transporters are known [11], GAT-1 is by far the dominant isoform in the rat hippocampus $[4,6,14]$. In order to identify the expression pattern of the main hippocampal GABA transporter we have

\footnotetext{
* Corresponding author. Tel.: +49-30-2802-6613; fax: +49-302802-6669.

E-mail address: christiane.frahm@charite.de (C. Frahm).
}

performed in situ hybridization against GAT-1 mRNA. For comparison, the distribution of interneurons was mapped by a combined probe for mRNA coding for both isoforms of the GABA-synthesized enzyme glutamate decarboxylase, GAD65/67 [7].

Adult (7-9 weeks) male and female Wistar rats were anaesthetized with chloralhydrate $(360 \mathrm{mg} / \mathrm{kg}$ body weight, i.p.) and perfused through the aorta with ice-cold saline (ca. $250 \mathrm{ml}$ ). Subsequently, the animals were decapitated, the brains rapidly removed, frozen in isopentane at $-30^{\circ} \mathrm{C}$ and stored at $-70^{\circ} \mathrm{C}$. Horizontal sections $(12 \mu \mathrm{m})$ were cut on a cryostat, mounted onto Superfrost-Plus slides (Fisher Scientific, Berlin, Germany) and kept at $-70^{\circ} \mathrm{C}$ until use.

For in situ hybridization, specific primers (Table 1) were designed based on published sequences for GAD65 [7], GAD67 [12] and GAT-1 [8]. We obtained rat cDNA sequences by PCR. Antisense and sense RNA probes were produced by in vitro transcription using T-overhang cloning vectors (Invitrogen, San Diego, USA/Promega, Mannheim, Germany/Amersham, Braunschweig, Germany). Probes were labelled with digoxigenin (RNA labelling kit, Boehringer, Mannheim, Germany). All transcripts were partially hydrolyzed into fragments of about $200 \mathrm{bp}$. Cryostat 
Table 1

Sequence information of primers ${ }^{a}$

\begin{tabular}{llll}
\hline Probe & & Primer sequence & $\begin{array}{l}\text { Probe } \\
\text { length (bp) }\end{array}$ \\
\hline GAT-1 & fw & GCCCCCTCATCACCCCTACACT & 647 \\
& rev & GCTTGTGGCTTTTCTTTTTCTC & \\
GAD65 & fw & CGGGCTCTGGCTTTTGTCC & 1680 \\
& rev & GGTTTGAGATGACCATGCGG & \\
GAD67 & fw & TAGAGACCCCAAGACCACCG & 1740 \\
& rev & GGGTTGGAGATGACCATCCG &
\end{tabular}

${ }^{a} \mathrm{bP}=$ number of basepairs; $\mathrm{fw}=$ foreward direction; rev $=$ reverse direction.

sections were fixed in $4 \%$ paraformaldehyde, acetylated in $0.1 \mathrm{M}$ triethanolamine containing $0.25 \%$ acetic anhydride and treated with $0.2 \mathrm{M} \mathrm{HCl}$ to enhance penetration of probe. Prior to hybridization, sections were dehydrated in graded ethanols and air dried. Slides were then incubated for $16 \mathrm{~h}$ at $55^{\circ} \mathrm{C}$ in hybridization buffer (Amersham) containing $3 \mu \mathrm{g} / \mathrm{ml}$ of digoxigenin labelled RNA probe. In experiments with a combined probe for GAD65 and GAD67 (see Results), the hybridization buffer contained $1.5 \mu \mathrm{g} / \mathrm{ml}$ of each RNA probe. The slides were washed for $10 \mathrm{~min}$ in $1 \times$ SSC with $0.1 \%$ SDS (sodium dodecyl sulfate), two times in $0.2 \times \mathrm{SSC}$ with $0.1 \%$ SDS each for $15 \mathrm{~min}$ at room temperature and two times in $0.1 \times \mathrm{SSC}$ with $0.1 \%$ SDS each for $15 \mathrm{~min}$ at $55^{\circ} \mathrm{C}$. This was followed by rinses in $2 \times$ SSC and then by immunodetection using a Nucleic Acid Detection Kit (Boehringer, Mannheim). The incubation in BCIP/NBT (5-bromo-4-chloro-3-indolyl phosphate/nitroblue tetrazolium chloride) colour solution was performed overnight. Then the sections were rinsed in water, air dried and mounted with Entellan (Merck, Darmstadt, Germany). The observations were carried out at light microscopic level using different magnifications $(\times 5$ to $\times 40)$. The microscope (Zeiss, Oberkochen, Germany) was equipped with a MC 80 photocamera.

In an initial series of experiments, we used separate probes for GAD65 and GAD67 (not shown). In accordance with published data [9] both GAD-probes yielded a grossly similar pattern of strongly labelled putative interneurons. A diffuse background staining of the dentate granule cell layer was, however, only observed with the GAD67 probe. In order to make sure that we marked all interneurons we then continued the analysis with a mixture of both probes (GAD65 + GAD67; referred to as 'GAD' from hereon). The distribution of cells was then compared to the pattern of GABA transporter mRNA. Stainings of the hippocampal sections for GAT-3 gave only minimal diffuse signals, in accordance with previous work $[5,14]$. The specificity of the GAT-3 mRNA probe was confirmed by the intense signals in thalamic nuclei [5]. Therefore, we restricted the analysis of hippocampal GABA-transporters to GAT-1. Sense probes gave no signal (Data not shown).

In situ hybridization for GAT-1 resulted in strong staining of numerous isolated cells in all extragranular/extrapyrami- dal layers (Fig. 1, left panels). In the area dentata, few cells were stained in the molecular layer, whereas the hilus showed numerous strongly stained cell bodies. The inner border of the granule cell layer was delineated by cells positive for GAD and -slightly less pronounced- for GAT1 mRNA (Fig. 1, top). The hippocampus proper showed few GAT-1 mRNA-positive cells in stratum oriens, while most cells were found at the transition from stratum radiatum to stratum lacunosum-moleculare (Fig. 1, left bottom). Some strongly stained cells were also present within stratum granulare and stratum pyramidale (Figs. 1 and 2, left panels). Based on the form and position of the labelled somata we found no indication for any astrocytic staining.

The distribution of cells containing GAT-1 mRNA was similar to that of putative interneurons labelled for GAD mRNA which yielded larger appearing and more homogeneously stained cell bodies (Figs. 1 and 2, right panels). In many slices, a cluster of strongly GAD-labelled cells was observed at the end of the suprapyramidal blade (Fig. 1, right panels). The number of cells stained for GAD in stratum oriens appeared slightly higher than for GAT-1, consistent with our previous findings [6]. Many of these cells were located at the outer border of stratum oriens and horizontally oriented (Fig. 1, right bottom). Like GAT-1, the probe for GAD mRNA strongly stained a small percentage of cells within the granule and pyramidal cell layer (Figs. 1 and 2, right panels). These data confirm that the majority of hippocampal interneurons express GAT-1 [5,14].

In addition, however, there was a diffuse background staining in the principal cell layers. This signal was strikingly different between GAT-1 and GAD: Whereas GAT-1 caused intense labelling of stratum granulare as well as stratum pyramidale throughout the hippocampus (Fig. 1, left panels), the GAD probe was almost undetectable in the pyramidal cell layers and showed only a faint staining of the granule cell layer (Fig. 1, right panels). This difference in staining of the excitatory cell layers was consistently found in all sections. At high magnification, the difference in the principal cell layer staining became even more obvious: GAT-1 (Fig. 2, left panels) apparently labelled most granule and pyramidal cell bodies with varying intensity (but always less than putative interneurons). In contrast, the GAD mRNA signal allowed only for the discrimination of faintly stained granule cells and was virtually absent in CA1 (Fig. 2, right panels).

The staining of principal, glutamatergic cells for GAT-1 mRNA may indicate the presence of the GABA transporter in these postsynaptic targets of inhibitory synapses, although this can not be strictly proven by in situ hybridization. It is unlikely that the observed 'background' staining is an artefact $[9,13]$ : we found consistent regional differences within the slices, no 'background' signal with all sense and with the GAT-3 probes, the hybridization protocol had high stringency and RNA probes were much longer (about 200 bp) than typical oligomers. Likewise, the GAD mRNA signal in granule cells indicates expression of the respective 

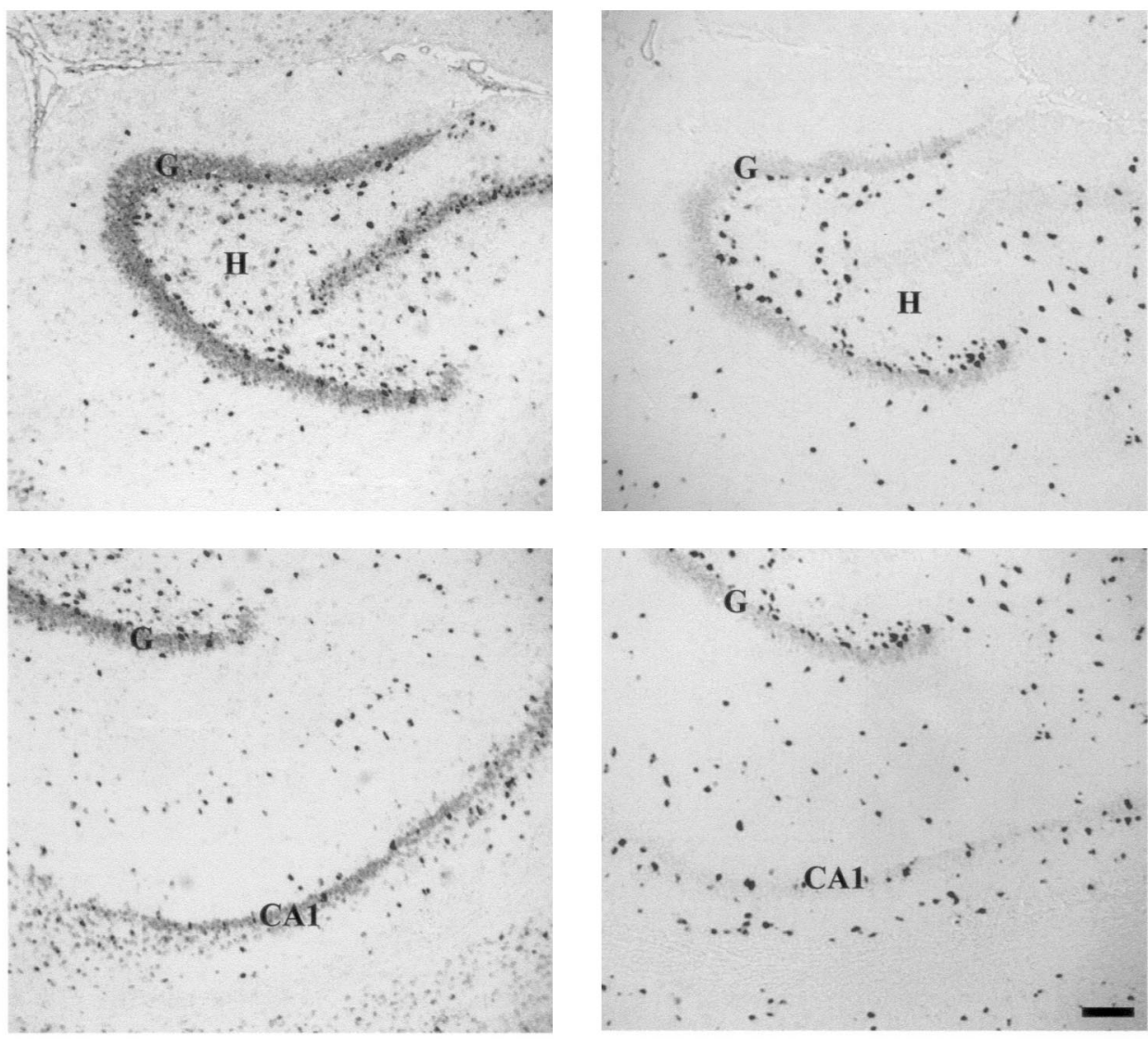

Fig. 1. Distribution of GAT-1 and GAD mRNA in the adult rat hippocampus. Left panels, in situ hybridization signal for GAT-1 mRNA; right panels, GAD mRNA. Top, dentate gyrus and CA3; bottom, CA1. Note the intense diffuse labelling of principal cell layers for GAT-1 mRNA in contrast to GAD. G, granular layer; $H$, hilus; CA1, region of the pyramidal cell layer. Scale bar $=400 \mu \mathrm{m}$.
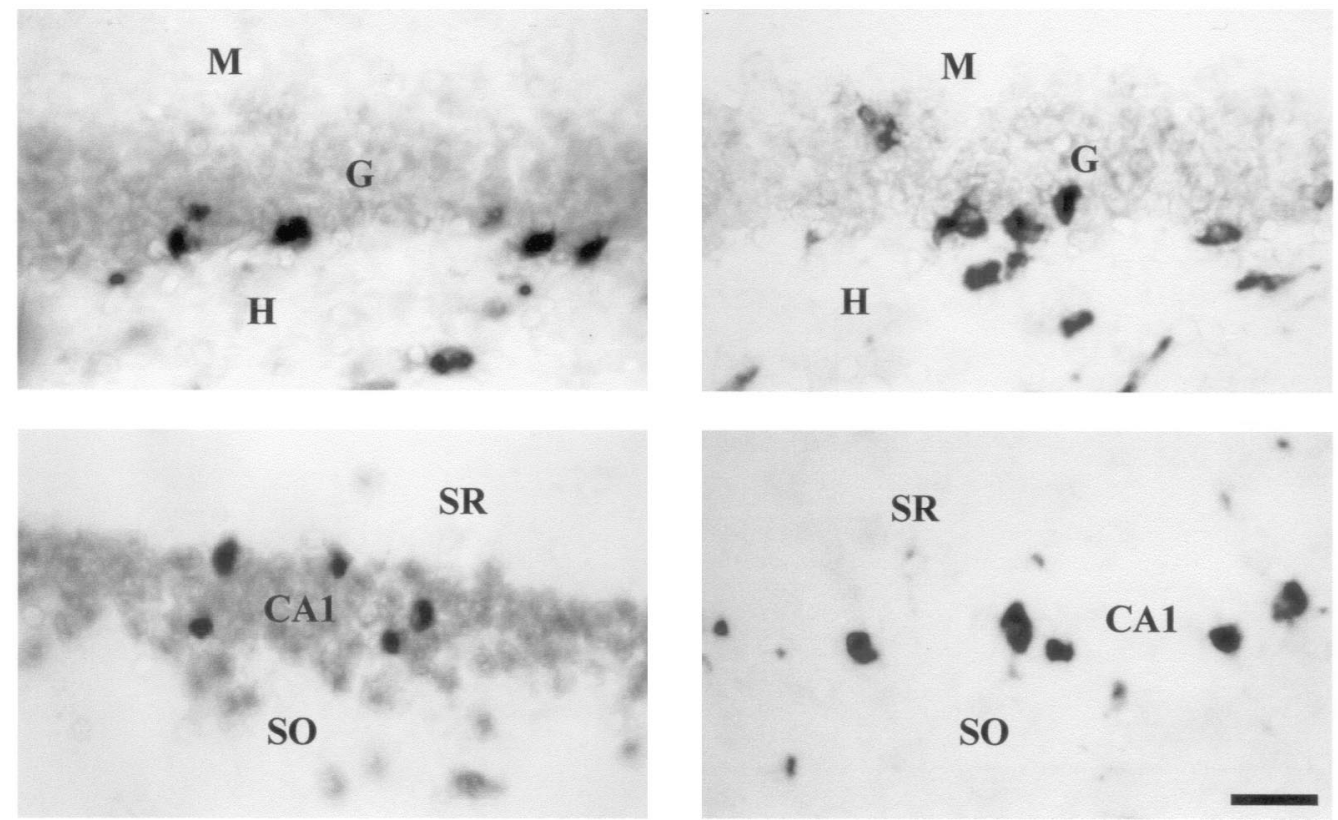

Fig. 2. Higher magnification of GAT-1 (left) and GAD (right) mRNA signal in the granular layer (top) and CA1 (bottom). Beside the interneurons most granule and pyramidal cells are stained for GAT-1 mRNA whereas the GAD probe shows only putative interneurons, except an extremely faint staining of the granule cell layer. $G$, granular layer; $H$, hilus; $M$, molecular layer; $C A 1$, region of the pyramidal cell layer; SR, stratum radiatum; SO, stratum oriens. Scale bar $=100 \mu \mathrm{m}$. 
enzyme and production of GABA, consistent with published data $[16,17]$. The existence of GAD mRNA in CA1 pyramidal cells has also been demonstrated using highly sensitive single-cell PCR methods [2]. Until now, no clear function can be assigned to GABA in glutamatergic cells. Assuming that the GAT-1 mRNA described in our study is translated into functional protein, it is feasible that principal cells release GABA by reversed transport [1] and thus contribute to tonic inhibition under certain conditions, e.g. in epilepsy. The expression of GABA transporters in nonGABAergic cells has also been suggested for the cortex, cerebellum and thalamic nuclei $[18,20]$. In the hippocampus, uptake of GABA through principal cells could, if present, help to clean the restricted extracellular space in the cell layers from GABA, released from the densely placed inhibitory terminals. Uptake of a major transmitter by neurons of different type has recently been described for GABAergic cerebellar Purkinje cells which take up glutamate [19].

In summary, our data show an overlapping expression of GAD and GAT-1 mRNA in hippocampal interneurons but a prominent staining of all hippocampal principle cell layers for GAT-1 mRNA. Functional studies have to reveal whether GABA can be removed from the extracellular space by glutamatergic cells.

The authors thank Dr Markus Numberger for helpful advice. Supported by the Deutsche Forschungsgemeinschaft, SFB 515/B1 (A.D.) and B7 (U.H.).

[1] Cammack, J.N., Rakhilin, S.V. and Schwartz, E.A., A GABA transporter operates asymmetrically and with variable stoichiometry, Neuron, 13 (1994) 949-960.

[2] Cao, Y., Wolcox, K.S., Martin, C.E., Rchinsky, T.L., Eberwine, J. and Dichter, M.A., Presence of mRNA for glutamate decarboxylase in both excitatory and inhibitory neurons, Proc. Natl. Acad. Sci. USA, 93 (1996) 9844-9849.

[3] Dingledine, R. and Korn, S.J., Gamma-aminobutyric acid uptake and the termination of inhibitory synaptic potentials in the rat hippocampal slice, J. Physiol. (Lond.), 366 (1985) 387-409.

[4] Draguhn, A. and Heinemann, U., Different mechanisms regulate IPSC kinetics in early postnatal and juvenile hippocampal granule cells, J. Neurophysiol., 76 (1996) 3983-3993.

[5] Durkin, M.M., Smith, K.E., Borden, L.A., Weinshank, R.L., Branchek, T.A. and Gustafson, E.L., Localization of mRNAs encoding three GABA transporters in rat brain: an in situ hybridization study, Mol. Brain Res., 33 (1995) 7-21.

[6] Engel, D., Schmitz, D., Gloveli, T., Frahm, C., Heinemann, U. and Draguhn, A., Laminar difference in GABA uptake and
GAT-1 expression in rat CA1, J. Physiol. (Lond.), 512 (1998) 643-649.

[7] Erlander, M.G., Tillakaratne, N.J.K., Feldblum, S., Patel, N. and Tobin, A.J., Two genes encode distinct glutamate decarboxylase, Neuron, 7 (1991) 91-100.

[8] Guastella, J., Nelson, N., Nelson, H., Czyzyk, L., Keynan, S., Miedel, M.C., Davidson, N., Lester, H. and Kanner, B., Cloning and expression of a rat brain GABA transporter, Science, 249 (1990) 1303-1306.

[9] Houser, C.R. and Esclapez, M., Localization of mRNAs encoding two forms of glutamic acid decarboxylase in the rat hippocampal formation, Hippocampus, 4 (1994) 530545.

[10] Krogsgaard-Larsen, P., Falch, E., Larsson, O.M. and Schousboe, A., GABA uptake inhibitors: relevance to antiepileptic drug research, Epilepsy Res., 1 (1987) 77-93.

[11] Liu, Q.R., Lopez-Corcuera, B., Mandiyan, S., Nelson, H. and Nelson, N., Molecular characterization of four pharmacologically distinct $\gamma$-aminobutyric acid transporters in mouse brain, J. Biol. Chem., 268 (1993) 2106-2112.

[12] Michelsen, B.K., Petersen, J.S., Boel, E., Moldrup, A., Dyrberg, T. and Madsen, O.D., Cloning, characterization, and autoimmune recognition of rat islet glutamic acid decarboxylase in insulin-dependent diabetes mellitus, Proc. Natl. Acad. Sci. USA, 88 (1991) 8754-8758.

[13] Rattray, M. and Priestley, J.V., Differential expression of GABA transporter-1 messenger RNA in subpopulations of GABA neurones, Neurosci. Lett., 156 (1993) 163-166.

[14] Ribak, C.E., Tong, W. and Brecha, N.C., The GABA plasma membrane transporters GAT-1 and GAT-3, display different distributions in the rat hippocampus, J. Comp. Neurol., 367 (1996) 595-606.

[15] Schousboe, A., Larsson, O.M., Wood, J.D. and KrogsgaardLarsen, P., Transport and metabolism of $\gamma$-aminobutyric acid in neurons and glia: implications for epilepsy, Epilepsia, 24 (1983) 531-538.

[16] Schwarzer, C. and Sperk, G., Hippocampal granule cells express glutamic acid decarboxylase-67 after limbic seizures in the rat, Neuroscience, 69 (1995) 705-709.

[17] Sloviter, R.S., Dichter, M.A., Rachinsky, T.L., Dean, E., Goodman, J.H., Sollas, A.L. and Martin, D.L., Basal expression and induction of glutamate decarboxylase and GABA in excitatory granule cells of the rat and monkey hippocampal dentate gyrus, J. Comp. Neurol., 373 (1996) 593-618.

[18] Swan, M., Najlerahim, A., Watson, R.E.B. and Bennett, J.P., Distribution of mRNA for the GABA transporter GAT-1 in the rat brain: evidence that GABA uptake is not limited to presynaptic neurons, J. Anat., 185 (1994) 315-323.

[19] Takahashi, M., Sarantis, M. and Attwell, D., Postsynaptic glutamate uptake in rat cerebellar Purkinje cells, J. Physiol. (Lond.), 497 (1996) 523-530.

[20] Yasumi, M., Sato, K., Shimada, S., Nishimura, M. and Tohyama, M., Regional distribution of GABA transporter 1 (GAT-1) mRNA in the rat brain: comparison with glutamic acid decarboxylase ${ }_{67}\left(G A D_{67}\right)$ mRNA localization, Mol. Brain Res., 44 (1997) 205-218. 